\title{
Enzymatic depolymerisation of cellulose
}

\author{
Helena Pala *, Manuel Mota, Francisco Miguel Gama * \\ Centro de Engenharia Biológica - IBQF, Universidade do Minho, Largo do Paço, 4719 Braga codex, Portugal \\ Received 8 June 2006; received in revised form 10 July 2006; accepted 13 July 2006 \\ Available online 30 August 2006
}

\begin{abstract}
Cellulose degree of polymerisation (DP) was determined in paper pulps and commercial powder celluloses before and after the enzymatic treatment with a blend of cellulases and hemicellulases. Three different methods were used: (i) chemical method, based on the measurement of the cellulose reducing power; (ii) viscosimetry; and (iii) gel permeation chromatography. Although based in very different principles, the three methods find similar DP values in the case of pure cellulose with narrow molecular weight distributions. The chemical method is more sensitive to detect enzymatic depolymerisation and appears to provide a good estimation of the number-average DP. GPC data offers more detailed information about the enzymes mode of action on the fibres, showing that cellulose hydrolysis in the presence of the commercial preparation Celluclast 1.5L follows a layer-by-layer solubilisation mechanism.
\end{abstract}

(c) 2006 Elsevier Ltd. All rights reserved.

Keywords: Cellulases; Degree of polymerisation (DP); Gel permeation chromatography (GPC); Paper pulps; Viscosimetry

\section{Introduction}

The technical properties of products such as pulp and paper (wood fibres), textile fabrics (cotton) or chemical cellulose (e.g. Avicel, used in the pharmaceutical industry) depend on cellulose characteristics, namely the degree of polymerisation (DP) (Eaton \& Hale, 1993). Light scattering, viscosimetry and gel permeation chromatography (GPC) are usual methods for measuring the polysaccharides DP (El Ashmawy, Daňhelka, \& Kössler, 1974; Valtasaari \& Saarela, 1975; Kleman-Leyer, Agosin, Conner, \& Kirk, 1992; Ramos, Nazhad, \& Saddler, 1993; Kleman-Leyer, Gilkes, Miller, \& Kirk, 1994; Pere, Siika-aho, Buchert, \& Viikari, 1995). As these methods are sensitive to different aspects of a sample, it is expected that the DP value provided varies according to the method used and to the complexity of the material. Therefore, it has been of interest for several authors to discuss the DP values obtained by using different methods. El Ashmawy et al. (1974) analysed bleached cellulosic pulps containing up to

\footnotetext{
* Corresponding authors. Tel.: +351253 604400; fax: +351253678986. E-mail address: helenads@estg.ipleiria.pt (H. Pala).
}

$20 \%$ hemicellulose and reported a good correlation between the viscosimetric and light scattering DP values of fractions purified by GPC. Ramos, Zandoná Filho, Deschamps, and Saddler (1999) used GPC in order to investigate the effect of several recombinant Trichoderma reesei cellulase preparations on the DP of a fully bleached pine Kraft pulp and found that their results followed the same trend as the ones reported by Pere et al. (1995), who used pulp viscosity measures in order to evaluate the effect of purified components of the $T$. reesei cellulase system on a unbleached pine Kraft pulp.

In this work, it is our purpose to discuss the correlation between the chemical (Gama, Teixeira, \& Mota, 1991; Gama, Faro, Teixeira, \& Mota, 1993; Gama \& Mota, 1997), viscosimetric (ISO 5351/1, 1981) and GPC (El Ashmawy et al., 1974; Valtasaari \& Saarela, 1975; Schroeder \& Haig, 1979; Kössler, Daňhelka, \& Netopilík, 1981; Ramos et al., 1993; Kleman-Leyer et al., 1994) methods when measuring the DP of samples with different complexity (wood pulps and commercial powder celluloses). Additionally, it is our goal to analyse the sensitivity of these methods to detect cellulose depolymerisation after an enzymatic treatment with a mixture of cellulases and hemicellulases from 
T. reesei. We specially aim at addressing the issue of the detection of the lower molecular weight (MW) molecules in the course of the digestion. It is, in fact, surprising that after treating a fully bleached Kraft pulp with $T$. reesei cellulase preparations exhibiting different endo/exo activities, Ramos et al. (1999) were not able to detect a significant modification on the low MW region $(\mathrm{DP}<100)$ of the GPC profiles. In this work, the use of the chemical method is expected to allow an improved detection of the enzymatic depolymerisation. The selection of a rather complex substrate/enzyme system to perform this study is related to the fact that cellulases and hemicellulases, which affect the cellulose DP, are able to improve the pulp and paper properties (Pommier, Fuentes, \& Goma, 1989; Jeffries, 1992; Stork \& Puls, 1995; Stork et al., 1995). The optimisation of such fibre treatment requires significant knowledge concerning enzyme performance (Pala, Lemos, Mota, \& Gama, 2001).

\section{Materials and methods}

\subsection{Materials}

In order to compare the different DP measures in samples with different degrees of complexity and chemical heterogeneity, the following samples were selected: (i) primary pulp (PP), used in paperboard production $(60 \%$ Pinus pinaster, 10\% Eucalyptus globulus and 30\% Pinus caribaea); (ii) secondary pulp (SP), obtained from recovered paperboard (60\% Kraft paper, $20 \%$ fluting and 20\% test liner); (iii) Sigmacell 101 (SiG), Sigma; (iv) Avicel, PH 101 (Avi), Fluka.

\subsection{Enzymes}

The enzymatic treatments were performed in the presence of a commercial cellulase from $T$. reesei, Celluclast $1.5 \mathrm{~L}$ (Novo Nordisk). The protein amount $(94 \mathrm{mg} / \mathrm{ml})$ was determined by the Bradford method, using serum albumin as standard (Bradford, 1976). Cellulase (57 FPU/ml), endoglucanase $(26 \mathrm{U} / \mathrm{ml})$ and xylanase $(680 \mathrm{U} / \mathrm{ml})$ activities were measured by the filter paper, carboxymethylcellulase and the xylan oat-spelt assays, respectively, as described in Wood and Bhat (1988) and in Bailey, Biely, and Poutanen (1992). Released sugars were measured by the dinitrosalicylic acid (DNS) method, using glucose as standard (Bernfeld, 1955).

\subsection{Enzymatic treatment}

Pulps. A mass equivalent to six oven-dried (o.d.) g of pulp was treated in sodium citrate buffer $0.05 \mathrm{M}, \mathrm{pH} 5.0$, in the presence of $2.8 \mathrm{FPU} / \mathrm{g}$ o.d. of Celluclast $1.5 \mathrm{~L}$. The enzyme was allowed to react with the pulp for $15 \mathrm{~min}$ and $4 \mathrm{~h}$, at 3\% consistency, with continuous slow mixing (approximately $35 \mathrm{rpm}$ ). Before being added to the reaction vessel, the enzymatic preparation was diluted (in $10 \%$ of the total reaction volume), in order to achieve a better dispersion. To finish up the trial, the enzyme was inactivated by boiling the pulp for $5 \mathrm{~min}$. The fibres were washed three times with sodium citrate buffer and were recovered by filtration. Each time, the filtrate was forced to pass through the fibre cake in order to avoid the loss of shorter fibres. The filtrates resulting from the first and the third washes were analysed for reducing sugars. Control assays (applying denatured enzyme) were made in parallel to the enzymatic ones.

Sigmacell. Cellulose $(10 \mathrm{mg}$ and $2 \mathrm{~g}$ samples $)$ was enzymatically treated ( 32 and $108 \mathrm{FPU} / \mathrm{g}$ ) as described above; the reactions took place at $0.5 \%$ consistency and $50 \mathrm{rpm}$ and the treated fibres were recovered by centrifugation.

\subsection{Quantification of cellulose degradation}

In order to accurately quantify the samples mass loss after the enzymatic treatment, the first-wash filtrate was incubated with $\beta$-glucosidase (Sigma) prior to the reducing sugars evaluation. The enzyme $(0.2 \mathrm{U} / \mathrm{g}$ pulp or cellulose) was added to the filtrate and left overnight at $40^{\circ} \mathrm{C}$. A long period of reaction was used in order to guarantee the complete reaction with $\beta$-glucosidase. After incubation, the reducing sugars were measured by the DNS method (Bernfeld, 1955). As an increased bond cleavage is obtained due to cellobiose hydrolysis to glucose, total reducing sugars determined after $\beta$-glucosidase action provides an overestimation of the extent to which cellulose was hydrolysed by the $T$. reesei cellulases $(\approx 20 \%)$.

The third filtrate presented no reducing sugars thus indicating that all soluble sugars were removed from the treated samples.

\subsection{Lignin content}

The amount of lignin present in the secondary and primary pulps (SP and PP) was determined after the Kappa number $(\mathrm{K})$ quantification (standard procedure T $236 \mathrm{~cm}$ 85). According to Tasman and Berzins (1957), for pulps obtained in yields up to $70 \%$, as is the case of SP and PP, the kappa number gives essentially a straight line relationship with lignin. For these pulps, the percentage of lignin approximately equals: $0.13 \times \mathrm{K}$.

\subsection{Degree of polymerisation measurement}

\subsubsection{Chemical method}

This method is based on the measurement of the insoluble fibres reducing power (IFRP) by the Nelson-Somogyi method (Nelson, 1944). Cellulose DP (DP chem $)$ is determined according to the equation $\mathrm{DP}=\mathrm{TC} * 1.1 / \mathrm{IFRP}$, where TC is the total cellulose dry-weight (determined after overnight drying at $100^{\circ} \mathrm{C}$ ) and 1.1 is the correction factor that expresses cellulose as glucose equivalents (Gama et al., 1991, 1993; Gama \& Mota, 1997). Three replicas were made for each sample. 


\subsubsection{Viscosimetric method}

This method is based on the measurement of the flowing time of a cellulose solution (using cuproethylenediamine as solvent) in a capillary viscosimeter at $25^{\circ} \mathrm{C}$. The intrinsic viscosity, $[\eta]$, of each solution is determined according to the Martin Equation (ISO 5351/1, 1981). DP values $\left(\mathrm{DP}_{\text {visc }}\right)$ are calculated by applying the Immergut formula: $\mathrm{DP}^{0.905}=0.805$. $[\eta]$ (Immergut, Schulz, \& Mark, 1953). The method was applied twice to each sample.

\subsubsection{Gel permeation chromatography method}

This method involves the polysaccharides chromatographic separation according to size. The cellulosic samples have first to react with phenylisocyanate to form derivatives suitable for the analysis (cellulose tricarbanilates). In the case of wood pulps, it is recommended the conversion into holocellulose (Schroeder \& Haig, 1979; Kössler et al., 1981) by the peracetic acid method (Browning, 1967), before derivatisation. Lignin removal is advantageous because it rends the polysaccharide more accessible to the derivatisation agents thus requiring softer experimental conditions during carbanilation, which reduces the risk of cellulose degradation (Schroeder \& Haig, 1979; Kössler et al., 1981). Moreover, the presence of carbanilated lignin in the derivatives $(>4 \%)$ can significantly affect the GPC profiles of the samples in the low molecular mass region (Kössler et al., 1981). The peracetic acid method is described by Browning (1967) as potentially non-degrading for cellulose and hemicellulose. Peracetic dosage, temperature and period of reaction were selected in order to conduct to the lowest polysaccharide loss (Browning, 1967). The yield after delignification was of about $80-85 \%$ holocellulose in all cases, which was considered as a sign of low polysaccharide loss.

Peracetic acid method. Pulp (2.5 g o.d.) was heated with $125 \mathrm{ml}$ of $10 \%$ peracetic acid in a bath at $90{ }^{\circ} \mathrm{C}$ for $30 \mathrm{~min}$. The suspension was then diluted with $125 \mathrm{ml}$ of water $\left(50^{\circ} \mathrm{C}\right)$ and the holocellulose was recovered by filtration; it was washed extensively with water at $50{ }^{\circ} \mathrm{C}$ and an acetone/alcohol mixture $(1: 1 \mathrm{v} / \mathrm{v})$ and finally dried at $45^{\circ} \mathrm{C}$.

Polysaccharide carbanilation. The derivatisation reaction took place in a $250 \mathrm{ml}$ reactor with controlled temperature and equipped with a condenser. Five hundred milligrams of dry holocelullose (or commercial powdered cellulose) was dissolved in $60 \mathrm{ml}$ of DMSO and kept overnight at $70{ }^{\circ} \mathrm{C}$ and constant magnetic stirring. Then, $10 \mathrm{ml}$ of phenylisocyanate was added and the mixture was kept under the same experimental conditions for $48 \mathrm{~h}$. To finish up the trial, $40 \mathrm{ml}$ of acetone was added to the mixture in order to decrease viscosity. The resulting solution was added to $1000 \mathrm{ml}$ of vigorously mixed alcohol to precipitate the cellulose tricarbanilates. The derivatives were recovered by filtration, washed with alcohol and dried in an oven at $50{ }^{\circ} \mathrm{C}$.

GPC analysis. The cellulose derivatives were dissolved in tetrahydrofuran (THF) and filtered through a teflon membrane with a pore size of $0.45 \mu \mathrm{m}$. The analysis was carried out at room temperature on a KNAUER liquid chromatograph using a series of three Chrompack Microgel columns with pores sizes of $10^{4}, 10^{5}$ and $10^{6} \AA$. Freshly purified THF was used as elution solvent at a flow rate of $0.8 \mathrm{ml} /$ $\min (2.8 \mathrm{MPa})$. The derivatives in the eluent were detected by a UV spectrophotometer (WellChrom K-2500) at the wavelength of $235 \mathrm{~nm}$. Because of the lack of commercially available standards of cellulose tricarbanilate, the system was calibrated with polystyrene standards with weight-average MW in the range 484-2,530,000 D. According to El Ashmawy et al. (1974), the polystyrene standards provide a good calibration for the GPC analysis of CTC. The correlation between both MW (cellulose trycarbanilate and polystyrene) was obtained by using the Mark-Houwink relationship as described in Valtasaari and Saarela (1975). The number-average and weight-average MW were then determined as $M_{\mathrm{n}}=\sum h_{\mathrm{i}} / \sum \frac{h_{\mathrm{i}}}{M_{\mathrm{i}}}$ and $M_{\mathrm{w}}=\left(\sum h_{\mathrm{i}} \times\right.$ $\left.M_{\mathrm{i}}\right) / \sum h_{\mathrm{i}}$, where $h_{\mathrm{i}}$ is the GPC curve height at the ith time increment and $M_{\mathrm{i}}$ is the molecular weight of the species eluted at the ith retention time (Yau, Kirkland, \& Bly, 1979). The apparent number-average and weight-average DPs $\left(D_{n}\right.$ and $\left.D_{w}\right)$ were calculated by dividing the respective MW values by 519 , the monomer equivalent weight of cellulose tricarbanilate.

\section{Results and discussion}

The present section is organised in two parts: in part (A) the untreated samples DP values are analysed in order to evaluate the correlation between the tested methods; in part (B) the enzymatically treated samples results are discussed in order to determine the effectiveness of each of the three methods to detect cellulose depolymerisation. Table 1 summarises these results.

\subsection{Cellulose DP: correlation between the chemical, viscosimetric and GPC methods}

As it was expected, different average DPs are obtained when each of the tested methods is used. Different physical and chemical properties are accessed during the DP measurements, namely the reducing power, the flow properties (viscosity) and the retention in a porous matrix, thus justifying these results. Shape, flexibility and hydration are characteristics that affect the viscosity and chromatographic retention time, having no effect on the reducing power. Moreover, different sample preparation routines were used, which can affect differently the cellulosic materials.

The first obvious conclusion arising from the analysis of Table 1 , is the $\mathrm{DP}_{\text {chem }} / \mathrm{DP}_{\mathrm{n}}$ and $\mathrm{DP}_{\mathrm{visc}} / \mathrm{DP}_{\mathrm{w}}$ similarities. The $\mathrm{DP}_{\text {chem }} / \mathrm{DP}_{\mathrm{n}}$ relationship is expected since the $\mathrm{DP}_{\text {chem }}$ and $\mathrm{DP}_{\mathrm{n}}$ calculations are identical: the average DP is a function of the number of molecules, its frequency and MW. Regarding both the $\mathrm{DP}_{\mathrm{w}}$ and $\mathrm{DP}_{\mathrm{visc}}$, it is recognized that the longer molecules have a corresponding larger weight on these DP values. The longer and more flexible molecules have an effect on viscosity that is more than 
Table 1

DP values obtained for the analysed materials by applying different methodologies

\begin{tabular}{|c|c|c|c|c|c|c|}
\hline Sample $^{\mathrm{a}}$ & $\%$ solubilisation & Chemical method & Viscosimetric method & GPC method $\left(\mathrm{DP}_{\mathrm{n}}\right)$ & GPC method $\left(\mathrm{DP}_{\mathrm{w}}\right)$ & $\mathrm{DP}_{\mathrm{w}} / \mathrm{DP}_{\mathrm{n}}$ \\
\hline \multicolumn{7}{|l|}{ Primary pulp (PP) } \\
\hline Control & 0 & 251 & 1617 & 251 & 2227 & 8.87 \\
\hline Enzymatic (15 min, 2.8 FPU) & 2 & 250 & 1377 & 241 & 2111 & 8.76 \\
\hline Enzymatic (4 h, 2.8 FPU) & 9 & 174 & 1162 & 244 & 2000 & 8.20 \\
\hline \multicolumn{7}{|l|}{ Secondary pulp (SP) } \\
\hline Control & 0 & 186 & 809 & 316 & 1777 & 5.62 \\
\hline Enzymatic (15 min, 2.8 FPU) & 3 & 154 & 626 & 221 & 1617 & 7.32 \\
\hline Enzymatic (4 h, 2.8 FPU) & 12 & 168 & 669 & 161 & 1511 & 9.39 \\
\hline \multicolumn{7}{|l|}{ Avicell } \\
\hline Blank & - & $134^{\mathrm{b}}$ & $112^{\mathrm{b}}$ & 129 & 302 & 2.34 \\
\hline \multicolumn{7}{|l|}{ Sigmacell 101} \\
\hline Control & 0 & 397 & 673 & 175 & 1592 & 9.10 \\
\hline Enzymatic (15 min, 32 FPU) & 8 & 352 & 663 & 118 & 1475 & 12.50 \\
\hline Enzymatic (4 h, 32 FPU) & 14 & 227 & 584 & 112 & 1493 & 13.33 \\
\hline Enzymatic (15 min, 108 FPU) & 36 & 297 & 589 & 119 & 1257 & 10.56 \\
\hline Enzymatic (4 h, 108 FPU) & 49 & 188 & 562 & 121 & 1407 & 11.63 \\
\hline
\end{tabular}

${ }^{\text {a }}$ Control values are the average of the measures in two samples.

b Values reported by Gama et al. (1991).

proportional to the $\mathrm{MW}$; as the solvent occupies a large part of the effective hydrodynamic sphere of the larger molecules, the smaller and stiffer molecules in a mixture have the lower contribution to the viscosity of the solution. The $\mathrm{DP}_{\mathrm{w}}$ depends on the weight-average MW of the solubilised molecules, which is particularly sensitive to the high-molecular-weight species.

The difference between $\mathrm{DP}_{\mathrm{n}}$ and $\mathrm{DP}_{\text {chem }}$ is more important for the paper pulp fibres and much less significant for the pure cellulose Avicel. In fact, the DP values provided by the three tested methods are remarkably coincident for Avicel (112, 129 and 134). This is, most likely, the consequence of the lower size heterogeneity of this commercial cellulose, with no lignin content. The chromatographic profiles in Fig. 1 reflect quite well the structural differences of the tested samples. It seems that as long as the analysed samples have homogeneous molecular size (narrow and symmetrical GPC curves), there is a good correlation between the different techniques. For the other samples, the DP evaluation by different techniques is possible but is not as simple.
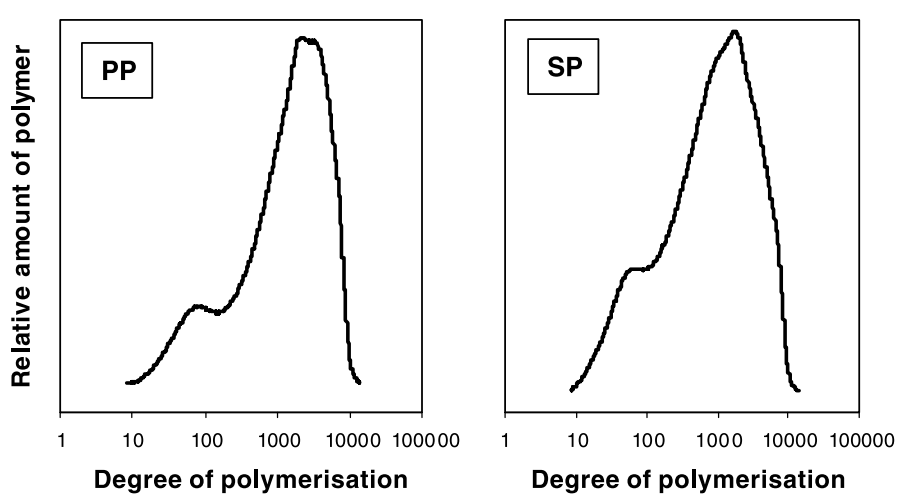
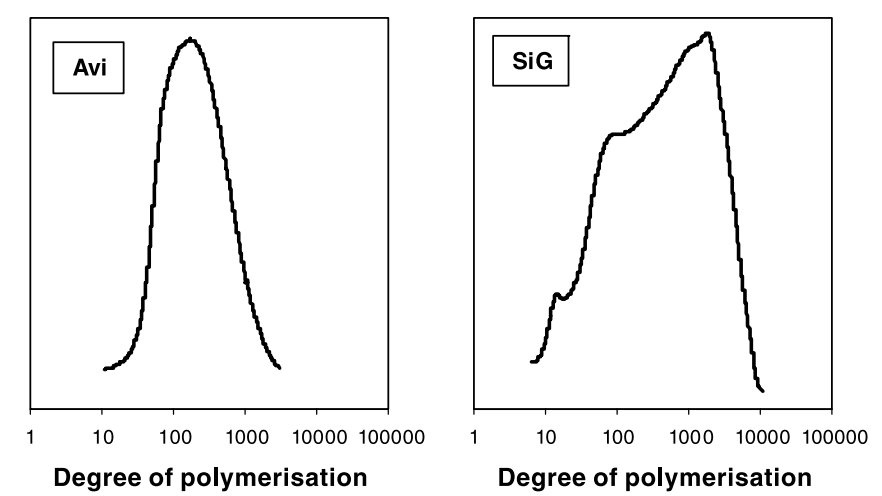

Relatively to the PP's (Fig. 1), the SP chromatographic profile shifts to lower DP positions, indicating that extensive depolymerisation occurs during the recycling process; the peak in SP becomes broader, reflecting the increase in the polydispersity of the sample and the presence of a wider range of molecular sizes. The high-DP maximum in the paper pulps' profiles ( $\mathrm{DP} \approx 2000)$ is due to cellulose, whereas the low-DP maximum (typically $\approx 100-200$ ) is indicative of the substantial hemicellulose content (Schroeder \& Haig, 1979; Ramos et al., 1999). Considering that after holocellulose preparation the PP and SP samples have low lignin content $(<4 \%)$, the GPC profile is probably not affected by the lignin derivatives at the lower DP positions of the curve (50-100) (Kössler et al., 1981; Liitiä, Maunu, \& Hortling, 2000).

The Avi/SiG different profiles (Fig. 1) are probably related with different preparation procedures. Avicel is a microcrystalline cellulose (MCC) and Sigmacell is a powdered cellulose (PC). MCC are partially hydrolysed celluloses prepared by hot-treating wood with strong acids, vigorous agitation of the slurry and spray drying. PC is

Degree of polymerisation

Fig. 1. Chromatographic profiles of different cellulosic materials. 
obtained by mechanically disintegrating wood and contains both irregularly shaped and different size particles (Doelker, Gurny, Schurz, Jánosi, \& Matin, 1987). The acid treatment leads to an extensive depolymerisation, while the mechanical treatment results in higher DP celluloses with increased polydispersity (Table 1).

As the GPC method gives detailed information about the MW distribution of the samples, it is expected to translate more effectively the average DP of the cellulosic material and to allow a better understanding of its properties. However, an accurate examination can not disregard the long and complex sample preparation methodology, which although described as "non-aggressive" to the analysed material, can in a few cases affect the GPC profiles at some extent (Browning, 1967; Valtasaari \& Saarela, 1975; Daňhelka, Kössler, \& Boháčková, 1976; Schroeder \& Haig, 1979; Kössler et al., 1981). In fact, the samples' modification during the solvent treatments and the derivatisation stage is not totally controlled, namely the loss of low molecular weight molecules and the degradation of the cellulosic material.

Nevertheless, the results obtained in this work are consistent with the ones reported by Schroeder and Haig (1979) and Ramos et al. (1993, 1999) for paper pulps $\left(\mathrm{GP}_{\mathrm{w}} \approx 1000-2000\right)$.

Concerning the chemical method, Gama et al. (1991) showed that the presence of polyphenolic compounds interferes with the colour development in the Nelson-Somogyi method. In the present work, the $\mathrm{DP}_{\text {chem }}$ values are generally in agreement with the $\mathrm{DP}_{\mathrm{n}}$ 's, showing that the chemical method is able to provide an accurate estimation of the average DP, even when the more complex and size-heterogeneous substrates are analysed. A comprehensive analysis of the $\mathrm{DP}_{\mathrm{n}} / \mathrm{DP}_{\text {chem }}$ correlation, using experimental conditions that avoid the errors resulting from the lignin interference (standard addition method) may demonstrate the usefulness of this fast and inexpensive method. According to this methodology, the Nelson-Somogyi routine would be applied to glucose standard samples and glucose standard samples containing the lignified pulp. Absorbence at $660 \mathrm{~nm}$ would be plotted against glucose concentration for all sets of analysis and a linear regression would be calculated for each one. For each trend line a value of $X$ when $Y=0$ would be computed. The accurate IFRP would be determined by $\mid X_{\text {glucose }}+$ pulp $-X_{\text {glucose }} \mid$. Additionally, $\mathrm{DP}_{\text {chem }}$ versus $\mathrm{DP}_{\text {visc }}$ seems to provide information on the size heterogeneity of the samples as reported by the $\mathrm{DP}_{\mathrm{w}} / \mathrm{DP}_{\mathrm{n}}$ ratio.

The presence of lignin in the paper pulps may also interfere with the $\mathrm{DP}_{\text {visc }}$ values by reducing the viscosity of the dissolved fibres in cuproethylenediamine. The Kraft process fragments lignin into lower MW pieces, which are partially removed from the wood; the remaining lignin has MW in the range of 35,000-64,000 (Liitiä et al., 2000). Considering the percentage of lignin in the PP and SP pulps $(7.8-10.4 \%$, Kappa number in the range $60-80)$, the $\mathrm{DP}_{\text {visc }}$ values of these samples were most likely affected. This effect may be less significant for the PP sample, where lignin depolymerisation is probably lower.

\subsection{Cellulose DP: enzymatic depolymerisation}

The analysis presented in this section is focused on the first minutes/hours of enzymatic reaction, as this is the condition required for enzymatic paper fibres upgrading (Pala et al., 2001). The enzymatic hydrolysis is highly dependent on the substrate structure (Lee, Kim, Ryu, \& Taguchi, 1983; Wong, Deverell, Mackie, \& Clark, 1988; Nazhad, Paszner, Saddler, \& Ramos, 1995; Gama \& Mota, 1997), thus explaining the release of different amounts of soluble sugars after the paper pulps treatment with the same enzyme dosage (Table 1). The presence of lignin affects the PP and SP pulps vulnerability to the enzymatic treatment. In fact, residual lignin strongly adheres to the cellulosic and hemicellulosic material (Simonson, 1971; Karlsson \& Westermark, 1996) thus restricting its availability to the enzymes action. Nevertheless, a short incubation period is sufficient to hydrolyse a significant amount of cellulose in all assays; a high hydrolysis rate occurs at the beginning of the enzymatic reaction and decreases throughout time.

After the enzymatic treatment, the same general trend on the DP variation is observed irrespective of the measuring technique: a slow but progressive decrease in DP values is detected in all Celluclast-treated samples (Table 1). The more significant DP variation occurs at the beginning of the reaction $(\approx 15 \mathrm{~min})$, which is in accordance with the higher solubilisation at that time; after that period, the DP variation is less important and suggests the decrease of the endoglucanase activity (Gama \& Mota, 1997). Although leading to the same conclusions, a different sensitiveness to depolymerisation is accessed by each method: both the chemical and viscosimetric methods seem to detect more accurately the DP values deviations.

As it was previously mentioned, after using different enzymes to degrade paper pulp fibres, Ramos et al. (1999) did not detect any substantial modification in the DP region bellow 100. This result was considered to be the consequence of an excess of cellobiase activity in all reaction trials, which would solubilise the low DP material that was being produced by the endo/exo enzymes. Nevertheless, the preservation of the GPC profiles in the low DP region is still somewhat unexpected. In fact, both the results presented by Ramos et al. (1999) and ours seem to provide evidence that the GPC method may not be very effective on detecting low MW material. On the contrary, the $\mathrm{DP}_{\text {chem }}$ measure is sensitive to all polymers because it is based on the detection of the cellulose molecules reducing ends and it is not directly dependent on the chain length. Additionally, it is possible that the chemical method, which involves a simpler sample manipulation, results in lower (if any) cellulose modification during the analytical procedure. 
Regarding viscosimetry, some caution must be taken when analysing enzymatic reactions of cellulose that develop differently from the ones reported here (for instance, a more rapid and/or extensive depolymerisation). In fact, Rinaudo (1988) reported that the viscosity measurements might provide little evidence of chain fission when oligomers are formed concurrently.

The evaluation of the complete GPC profiles of the enzymatically treated paperboard pulps (PP, SP) and respective controls provide information about the enzymatic modification of the samples (Figs. 2 and 3) and allow the identification of an hydrolytic pattern for the Celluclast enzymes. The enzymatically treated PP profiles slightly deviate to a lower DP range; this phenomenon is more evident after a 4-h treatment (Fig. 2). The slight decrease of the lower DP molecules in the 15-min enzymatically treated sample is probably related to the enzymatic action of celobiohydrolases (CBH). In fact, Ramos et al. (1999) detected the accumulation of intermediate MW material after a treatment with $\mathrm{CBH}$-deficient enzyme preparations from T. reesei, thus showing that this activity is essential to the degradation of the lower chain length cellulose molecules. As the reaction proceeds, endoglucanase (EG) activity further depolymerises the substrate and the relative portion of lower MW molecules increases steadily along with the digestion time; as the $\mathrm{CBH}$ activity is probably not sufficient to hydrolyse all of the released material, the smallest molecules accumulate in the reaction mixture. The T. reesei's EG ability to change DP is already well documented. Ramos et al. (1999) reported a lower depolymerisation after treatment with EG-deficient enzymes. Pere et al. (1995) reported a significant viscosity decrease after the pulp treatment with pure EG; additionally, these authors related this modification to a significant decrease in paper strength thus showing the importance of the enzymes mode of action in the technical properties of the final product.

Regarding the SP profiles (Fig. 3), the enzymatically treated MW distribution becomes broader, the peaks at
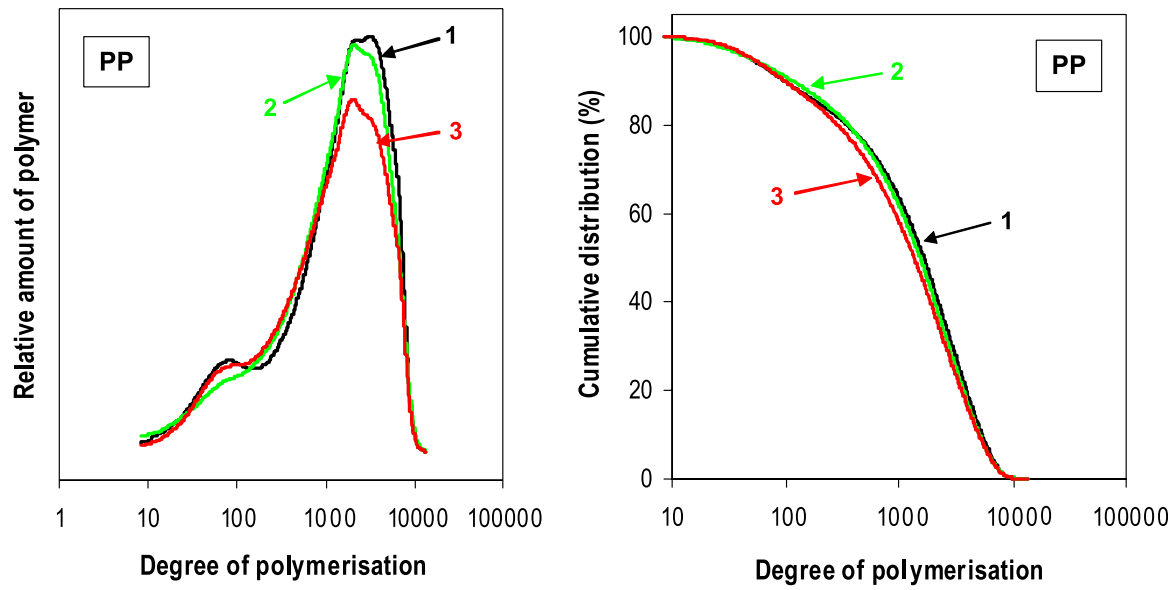

Fig. 2. (left) Chromatographic profiles for the enzymatically treated PP. The areas under the curves have been adjusted to reflect weight loss due to the enzymatic activity. (right) DP cumulative distributions for the enzymatically treated PP. The cumulative values were calculated from the GPC analysis. (1) Average control (2) enzymatically treated $(15 \mathrm{~min})$ and (3) enzymatically treated (4 h).
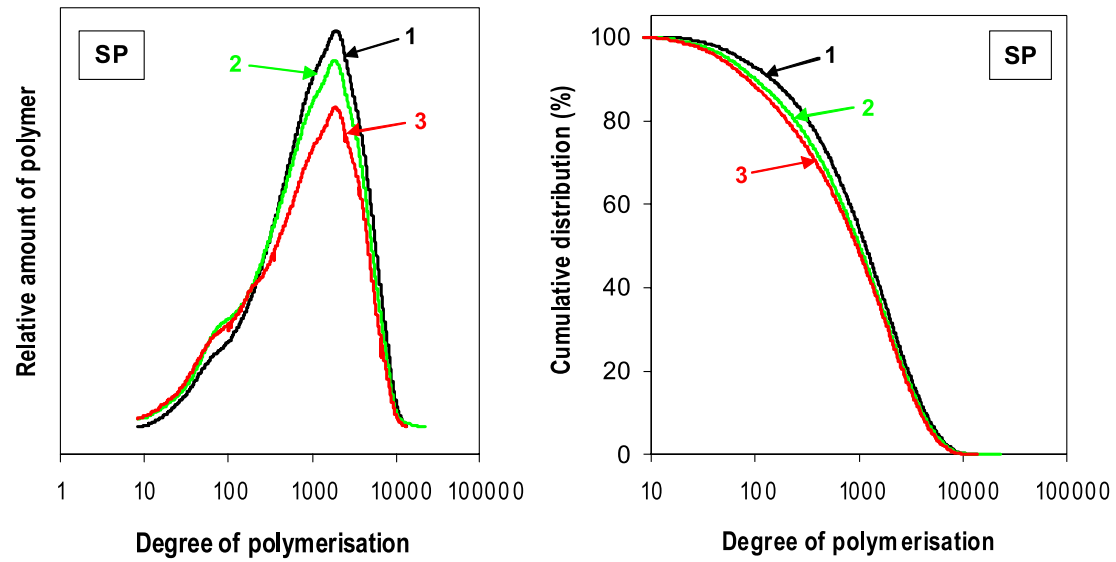

Fig. 3. (left) Chromatographic profiles for the enzymatically treated SP. The areas under the curves have been adjusted to reflect weight loss due to the enzymatic activity. (right) DP cumulative distributions for the enzymatically treated SP. The cumulative values were calculated from the GPC analysis. (1) Average control (2) enzymatically treated (15 min) and (3) enzymatically treated (4 h). 

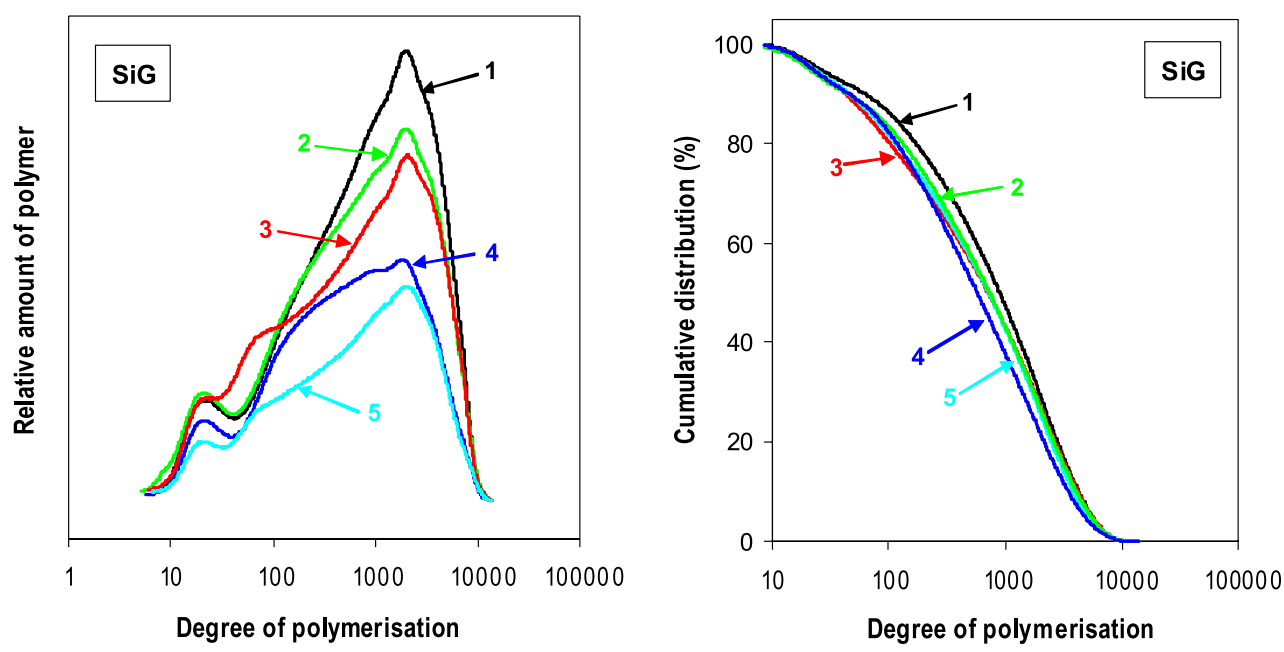

Fig. 4. (left) Chromatographic profiles for the enzymatically treated Sigmacell. The areas under the curves have been adjusted to reflect weight loss due to the enzymatic activity. (right) DP cumulative distributions for the enzymatically treated Sigmacell. The cumulative values were calculated from the GPC analysis. (1) Average control (2) enzymatically treated (32 FPU/15 min) (3) enzymatically treated (32 FPU/4 h) (4) enzymatically treated (108 FPU/ $15 \mathrm{~min})$ and (5) enzymatically treated (108 FPU/4 h).

the high DP position become shorter and the peaks at low DP become more evident. The broadening of the major peak in the molecular-size distribution profiles led to a gradual increase in the polydispersity of the samples, as shown in Table 1. Although the mechanism involved in the SP solubilisation appears to be similar to the one described before, this pulp seems to be less resistant to the enzymatic treatment, almost certainly as a consequence of the previous papermaking cycles. In fact, further lignin fragmentation and hemicellulose liberation probably occurs thus increasing the fibbers porosity and consequently the cellulose exposure to the enzymes. Fig. 3 shows that for the SP sample hydrolysis caused a quicker shifting in the MW distribution of cellulose toward low-MW positions than in the PP sample (Fig. 2).

The profiles shifting during SP and PP reactions looks equivalent to the one obtained by Ramos et al. (1993, 1999), when analysing fully bleached Kraft pulps derived from eucalyptus (screened fractions) and from pine (nonfractionated pulp), after treatment with Celluclast supplemented with $\beta$-glucosidase. To explain the progressive enzymatic depolymerisation, Kleman-Leyer et al. (1992, 1994) suggested that enzymes act preferentially on fibre surface by degrading the more accessible regions of the substrate. Indeed, this mechanism seems appropriate to explain the modifications observed in the present work for very different materials such as the primary and secondary pulps and Sigmacell.

In the case of Sigmacell, an important modification of the GPC profiles occurs just at the beginning of the reaction (Fig. 4, left). As a result of the higher enzyme dosage used in these assays, an increased amount of lower and intermediate molecular weight molecules is visible at this early stage (Fig. 4, right). Considering the same enzyme dosage (32 or 108 FPU), the chromatographic profiles tend to become broader for extended reaction periods ( 15 min versus $4 \mathrm{~h}$;
Fig. 4, left) thus reflecting the samples' increased polydispersity (Table 1). Kleman-Leyer et al. (1994) detected a similar trend after treating cotton cellulose with the recombinant CenA endoglucanase. After a $49 \%$ cellulose solubilisation treatment, the higher molecular weight fraction produces a sharper peak in the GPC record, suggesting that this residual sample is more difficult to hydrolyse (Fig. 4, left).

In all cases, even after long digestion periods (corresponding to $9-49 \%$ solubilisation, depending on the sample and enzyme concentration), most of the high-MW cellulose still remains intact, reinforcing that the digestion follows a layer-by-layer solubilisation pattern.

\section{Acknowledgements}

The authors thank University of Beira Interior - Department of Paper Science and Technology the use of the laboratory facilities for the viscosimetric measurements and Portucel Viana for kindly supplying the PP/SP samples.

\section{References}

Bailey, M. J., Biely, P., \& Poutanen, K. (1992). Interlaboratory testing of methods for assay of xylanase activity. Journal of Biotechnology, 23, 257-270.

Bernfeld, P. (1955). Amylases, $\alpha$ and $\beta$. Methods in Enzymology, 1(17), 149-152.

Browning, B. L. (1967). Methods of wood chemistry. NY: WileyInterscience, II (19) 388-403.

Daňhelka, J., Kössler, I., \& Boháčková, V. (1976). Determination of molecular weight distribution of cellulose by conversion into tricarbanilate and fractionation. Journal of Polymer Science, 14, 287-298.

Doelker, E., Gurny, R., Schurz, J., Jánosi, A., \& Matin, N. (1987). Degrees of crystallinity and polymerisation of modified cellulose powders for direct tableting. Powder Technology, 52, 207-213.

Eaton, R. A., \& Hale, M. D. C. (1993). Wood-decay, pest and protection. London: Chapman and Hall, Chap. 1, 1-37.

El Ashmawy, A. E., Daňhelka, J., \& Kössler, I. (1974). Determination of molecular weight distribution of cellulosic pulps by conversion into 
tricarbanilate, elution fractionation and GPC. Svensk Papperstidning, 16, 603-608.

Gama, F. M., Faro, C. J., Teixeira, J. A., \& Mota, M. (1993). New methodology for characterisation of endoglucanase activity and its application on the Trichoderma longibrachiatum cellulolytic complex. Enzyme and Microbial Technology, 15, 57-61.

Gama, F. M., \& Mota, M. (1997). Enzymatic hydrolysis of cellulose (I): relationship between kinetics and physico-chemical parameters. Biocatalysis and Biotransformation, 15, 221-236.

Gama, F. M., Teixeira, J. A., \& Mota, M. (1991). Direct determination of endoglucanase activity on cellulose insoluble fibres. Biotechnology Techniques, 5(5), 377-382.

Immergut, E. H., Schulz, J., \& Mark, H. (1953). Monatshehefte für Chemie, 84, 219-249.

ISO 5351/1 (1981). Cellulose en solutions diluées - Détermination de l'indice de viscosité limite - Partie 1: Méthode utilisant une solution de cupri-éthylène-diamine (CED).

Jeffries, T. W. (1992). Enzymatic treatments of pulps. American Chemical Society Symposium Series, 476(18), 313.

Karlsson, O., \& Westermark, U. (1996). Evidence for chemical bonds between lignin and cellulose in Kraft pulps. Journal of Pulp and Paper Science, 22(10), J397-J401.

Kleman-Leyer, K. M., Agosin, E., Conner, A. H., \& Kirk, T. K. (1992). Changes in the molecular size distribution of cellulose during attack by white rot and brown rot fungi. Applied and Environmental Microbiology, 58(4), 1266-1270.

Kleman-Leyer, K. M., Gilkes, N. R., Miller, R. C., Jr., \& Kirk, T. K. (1994). Changes in the molecular-size distribution of insoluble celluloses by the action of recombinant Cellulomonas fimi cellulases. Biochemical Journal, 302, 463-469.

Kössler, I., Daňhelka, M., \& Netopilík, M. (1981). The carbanilate method for determination of the degree of polymerisation of cellulose. Svensk Papperstidning, 18, R137-R140.

Lee, S. B., Kim, I. H., Ryu, D. D. Y., \& Taguchi, H. (1983). Structural properties of cellulose and cellulase reaction mechanism. Biotechnology and Bioengineering, $X X V, 33-51$.

Liitiä, T., Maunu, S. L., \& Hortling, B. (2000). Solid-state NMR studies of residual lignin and its association with carbohydrates. Journal of Pulp and Paper Science, 26(9), 323-330.

Nazhad, M., Paszner, L., Saddler, J. N., \& Ramos, L. P. (1995). Structural constraints affecting the initial enzymatic hydrolysis of recycled paper. Enzyme and Microbial Technology, 17(1), 68-74.

Nelson, N. J. (1944). A photometric adaptation of the Somogyi method for the determination of glucose. Journal of Biological Chemistry, 153, 375-380.

Pala, H., Lemos, M. A., Mota, M., \& Gama, F. M. (2001). Enzymatic upgrade of old paperboard containers. Enzyme and Microbial Technology, 29, 274-279.
Pere, J., Siika-aho, M., Buchert, J., \& Viikari, L. (1995). Effects of purified Trichoderma reesei cellulases on the fiber properties of Kraft pulp. Tappi Journal, 78(6), 71-78.

Pommier, J. C., Fuentes, J. L., \& Goma, G. (1989). Using enzymes to improve the process and the product quality in the recycled paper industry. Part 1: the basic laboratory work. Tappi Journal, 72(6), 187-191.

Ramos, L. P., Nazhad, M. M., \& Saddler, J. N. (1993). Effect of enzymatic hydrolysis on the morphology and fine structure of pretreated cellulosic residues. Enzyme and Microbial Technology, 15, 821-831.

Ramos, L. P., Zandoná Filho, A., Deschamps, F. C., \& Saddler, J. N. (1999). The effect of Trichoderma cellulases on the fine structure of a bleached softwood Kraft pulp. Enzyme and Microbial Technology, 24, 371-380.

Rinaudo, M. (1988). On the use of a viscosimetric method with a CMC solution to monitor endoglucanase activity. In J. P. Aubert, P. Beguin, \& J. Millet (Eds.), Proceedings of the symposium on biochemistry and genetics of cellulose degradation (pp. 385-391). New York: Academic Press.

Schroeder, L. R., \& Haig, F. C. (1979). Cellulose and wood pulp polysaccharides. Gel permeation analysis. Tappi, 62(10), 103-105.

Simonson, R. (1971). The hemicellulose in the sulfate pulping process. Svensk Papperstidning, 74(21), 691-700.

Stork, G. Puls, J. (1995). Change in properties of different recycled pulps by endoglucanase treatment. In 6th international conference on biotechnology in the pulp and paper industry pp. (145-150).

Stork, G., Pereira, H., Wood, T. M., Düsterhöft, E. M., Toft, A., \& Puls, J. (1995). Upgrading recycled pulps using enzymatic treatment. Tappi Journal, 78(2), 79-88.

T $236 \mathrm{~cm}-85$, Kappa number of pulp.

Tasman, J. E., \& Berzins, V. (1957). The permanganate consumption of pulp materials. I. Development of a basic procedure. II. The Kappa number. III. The relationship of the kappa number to the lignin content of pulp materials. Tappi, 40(9), 691-704.

Valtasaari, L., \& Saarela, K. (1975). Determination of chain length distribution of cellulose by gel permeation chromatography using the tricarbanilate derivative. Paperi Puu, 1, 5-10.

Wong, K. K. Y., Deverell, K. F., Mackie, K. L., \& Clark, T. A. (1988). The relationship between fiber porosity and cellulose digestibility in steam-exploded Pinus radiata. Biotechnology and Bioengineering, 31, 447-456.

Wood, T. M., \& Bhat, K. M. (1988). Methods for measuring cellulase activities. Methods in Enzymology, 160(9), 87-112.

Yau, W. W., Kirkland, J. J., \& Bly, S. D. (1979). Modern sizeexclusion liquid chromatography: Practice of gel permeation and gel filtration chromatography. NY: Wiley-Interscience, Chap. 1, 9 and 10. 